\title{
Corrigendum: Testing by Non-Destructive Control
}

\begin{abstract}
${ }^{1}$ Relly Victoria Virgil Petrescu, ${ }^{2}$ Raffaella Aversa, ${ }^{3}$ Bilal Akash, ${ }^{4}$ Ronald Bucinell, ${ }^{5}$ Juan Corchado, ${ }^{6}$ Samuel P. Kozaitis, ${ }^{7}$ Taher M. Abu-Lebdeh, ${ }^{2}$ Antonio Apicella and ${ }^{1}$ Florian Ion Tiberiu Petrescu
\end{abstract}

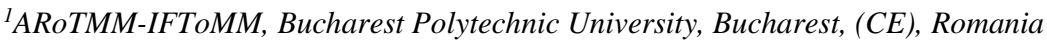 \\ ${ }^{2}$ Advanced Material Lab, Department of Architecture and Industrial Design, \\ Second University of Naples, 81031 Aversa (CE), Italy \\ ${ }^{3}$ Dean of School of Graduate Studies and Research, American University of Ras Al Khaimah, UAE \\ ${ }^{4}$ Union College, USA \\ ${ }^{5}$ University of Salamanca, Spain \\ ${ }^{6}$ Florida Institute of Technology, USA \\ ${ }^{7}$ North Carolina A and T State University, USA
}

Correction to: American Journal of Engineering and Applied Sciences http://doi.org/10.3844/ajeassp.2017.568.583, published online 05 June 2017; updated 29 August 2019

The original version of this Article contained Mr. MirMilad Mirsayar as a CoAuthor. Mr. Mirsayar has not contributed to the preparation and publication of this manuscript.

These errors have now been corrected in the HTML and PDF versions of the Article. http://doi.org/10.3844/ajeassp.2017.568.583. 